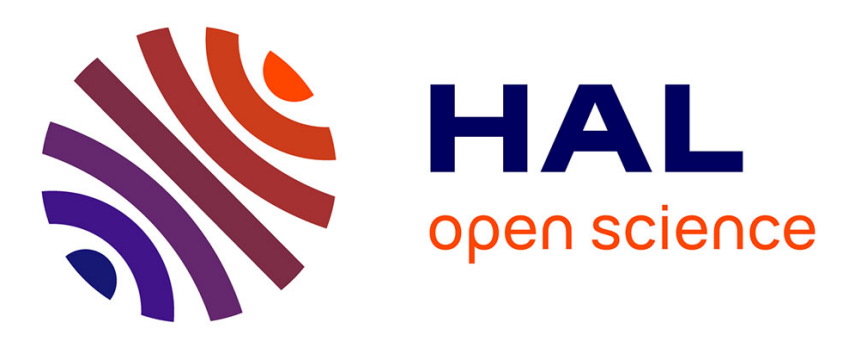

\title{
Real-Time Wideband Acoustic Signal Processing for Fish Counting
}

Gabriel Vasile, Pascal Bellemain, Guy d'Urso, Eric de Oliveira

\section{To cite this version:}

Gabriel Vasile, Pascal Bellemain, Guy d'Urso, Eric de Oliveira. Real-Time Wideband Acoustic Signal Processing for Fish Counting. OCEANS 2018 - OCEANS '18 MTS/IEEE. Healthy Oceans, Resilient Coasts, Robust Commerce... Strong Nations, Oct 2018, Charleston, United States. hal-01935323

\section{HAL Id: hal-01935323 https://hal.science/hal-01935323}

Submitted on 26 Nov 2018

HAL is a multi-disciplinary open access archive for the deposit and dissemination of scientific research documents, whether they are published or not. The documents may come from teaching and research institutions in France or abroad, or from public or private research centers.
L'archive ouverte pluridisciplinaire HAL, est destinée au dépôt et à la diffusion de documents scientifiques de niveau recherche, publiés ou non, émanant des établissements d'enseignement et de recherche français ou étrangers, des laboratoires publics ou privés. 


\section{Real-Time Wideband Acoustic Signal Processing for Fish Counting}

\author{
Gabriel Vasile, Pascal Bellemain \\ Grenoble-Image-sPeech-Signal-Automatics Lab \\ CNRS / Université Grenoble Alpes \\ 11 rue des Mathématiques \\ Grenoble Cedex, France, F-38402 \\ gabriel.vasile@gipsa-lab.grenoble-inp.fr
}

\author{
Guy d'Urso and Eric De Oliveira \\ Electricité de France \\ EDF R\&D, STEP / LNHE \\ 6 quai Watier \\ Chatou, France, F-78400 \\ guy.durso@edf.fr, eric.de-oliveira@edf.fr
}

\begin{abstract}
This paper proposes an IoT active acoustic system for fish monitoring with direct application in biodiversity preservation near hydropower plants and dams. The system employs a cost effective single board computer as central processing unit. The acoustic signal processing is performed at two levels: the first at the board level (embedded), to decide upon transmission of data to a server, and the server level to show the results of detection and the number of fish passages (acoustic signature analysis). The performance analysis of the proposed fish monitoring system is carried out during a four days experimental campaign in Chatou, France.
\end{abstract}

\section{INTRODUCTION}

Dam and hydropower plants are currently known to obstruct migration of fish species along the watercourses during certain phases of their lifetime. However, the 2030 Climate and Energy Framework, agreed in 2014, imposed to reduce carbon footprint by $40 \%$ [1], which makes this renewal energy more and more used. We are in the situation of trading the preservation of fish biodiversity against the production of clean energy and, hence, there is a stringent search for alternative measures to mitigate the impact on biodiversity. A popular approach is to construct channels where the fish by-pass the targeted hydraulic installations.

In this work, we present the signal processing algorithms embedded in our prototype IoT (Internet of Things) acoustic system for fish activity monitoring, with the objective to count the fish getting through any by-pass channel. In a separate paper proposed to the same conference, we have already presented the hardware configuration of the system. Illustrated in the Fig. 1, it contains a FPGA based single board computer for both signal acquisition and arbitrary function generation (RedPitaya STEMLab 125-14, RP), 2 transmitting ultrasound transducers (Ultran Group WS-100-1), 2 ultrasound transducers in reception (KS-100-1), a power amplifier (APEX Microtechnology PA107), a low noise amplifier(TI VCA 5807) and a server for real-time signal processing (Intel NUC). The sensors are calibrated by sphere-calibration method as described in [2].

The paper is structured as follows. Section II illustrates in several steps the proposed software architecture of underwater fish monitoring system, while Section III presents both qual-

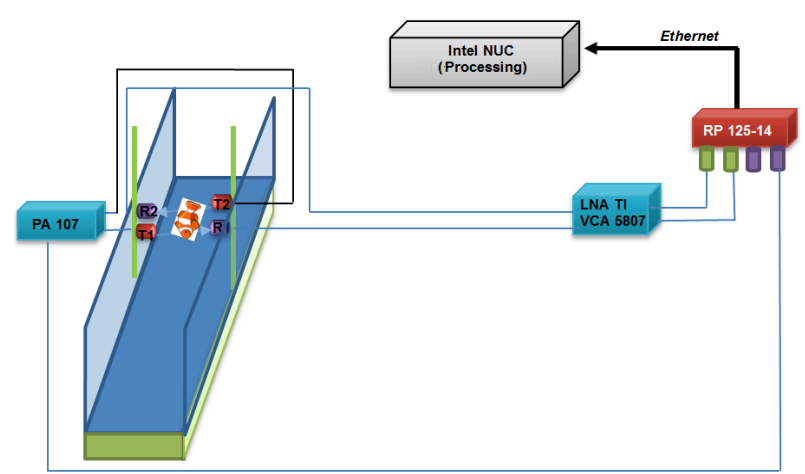

Fig. 1. Setup for fish counting experiments.

itative and quantitative performance assessment. Section IV concludes the paper.

\section{IOT SOFTWARE ARCHITECTURE}

The proposed signal processing algorithm operates in realtime and it is composed of two stages:

- the IoT client - an embedded system capable of managing signal acquisition, real time processing (intelligent triggering option) and sending the recorded data to the server ;

- the IoT server - a processing unit for data management, storage and final signal processing.

The former is considered in taking decisions to transmit the acoustic signature (or not) to the server (energy saving) for further analysis, whereas the latter is used for detecting, recognising and counting the fish passages.

\section{A. IoT client}

The client software has been developed in $\mathrm{C}$ using the POSIX threads / sockets and the RedPitaya libraries on the embedded Ubuntu operating system. The software is continuously configuring and controlling emission, reception and data transmission in real time using parallel threading on the embedded coprocessor.

The RP board's arbitrary function generator is programmed to transmit Hamming weighted linear frequency modulation 
signals (chirps) [3] in the band comprised between $350 \mathrm{kHz}$ and $650 \mathrm{kHz}$. Each reception has $2 \times 16384$ samples stored on a single "signed short" vector. In order to achieve better transmission results, the last $N=100$ recorded signals are locally stored in a circular buffer. Once this buffer is filled with data, it is send to the IoT server via a TCP socket. The flowchart of the embedded signal processing algorithm is presented in Fig. 2.

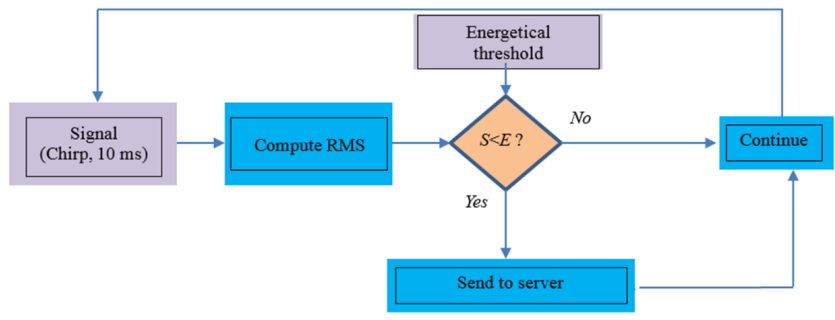

Fig. 2. Flowchart of the embedded signal processing algorithm.

At each data transmission iteration, we proposed an algorithm to select eventual passages within the acoustic channel: the RMS value is computed for each recorded signal and the $50 \%$ and $5 \%$ quantiles are computed. The data is transmitted to the IoT server only if their ratio is inferior to $3 \mathrm{~dB}$. Hence, the algorithm decides if the signal is to be sent for further signal processing to the NUC server. The entire acquisition process is real-time thanks to the possibility to program the RP board using POSIX thread and sockets libraries.

\section{B. IoT server}

Regarding the processing stage on the NUC server, the received chirps from the RP board are matched filtered (MF). The reference signals used in the matched filtering are computed as in [4] over the most recent 200 received signals, making the fish detection application adaptive to the current underwater environment. After MF, the results are expressed in terms of RMS amplitudes. Due to the fish passage between two sensors (Tx/Rx), the RMS amplitude drops in value because of propagation channel attenuation. This way, it allows fish counting continuously.

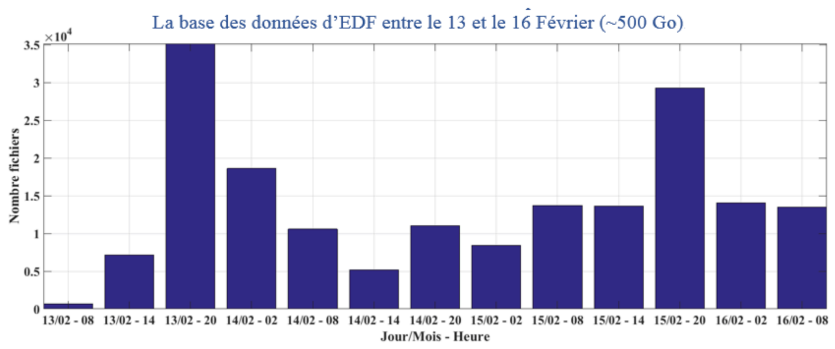

Fig. 3. Number of files stored on the IoT server during the Chatou measurement campaign.

Finally, Fig. 3 illustrates the number of files (which corresponds to each detection) stored by the IoT server during a 4-days measurement campaign.

\section{RESUlTS AND DISCUSSION}

This paper investigates the first results obtained using the proposed real-time wideband acoustic fish monitoring system experimented in February 2018 at the EDF R\&D headquarters in Chatou, France. Several types of targets that were inspected (wood branches, rocks, live bait fish and salmon) are illustrated in Fig. 4. One of the main objectives of this campaign was the study of trout acoustic signatures, also.
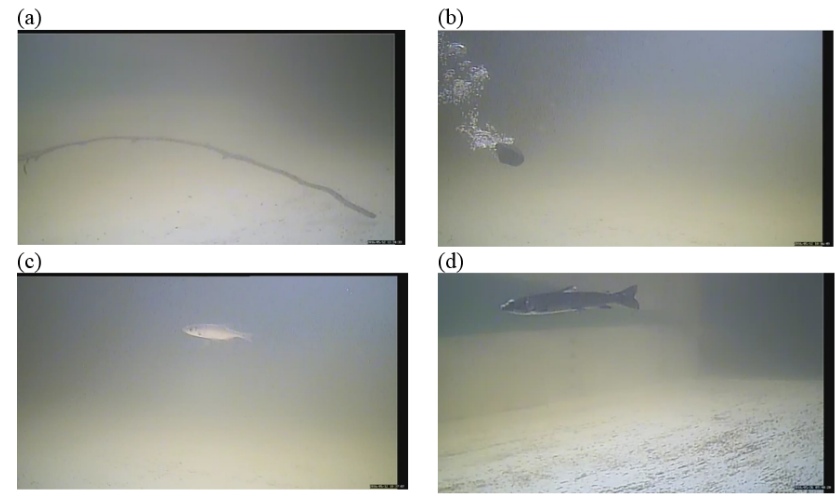

Fig. 4. Different targets selected for the measurement campaign: (a) Branche - small wood branch, (b) Cailloux - small rock, (c) Gardon - live fishing bait and (d) Saumon - salmon.

In order to investigate weather the spectral diversity can be able to distinguish different types of targets passing through an acoustic barrier, Fig. 5 shows the spectrum of each of the four target signatures. One can notice a clear decrease in energy around $450 \mathrm{kHz}$ for the fish passages, only. This indicates the capabilities to distinguish different types of targets using wideband signal processing.

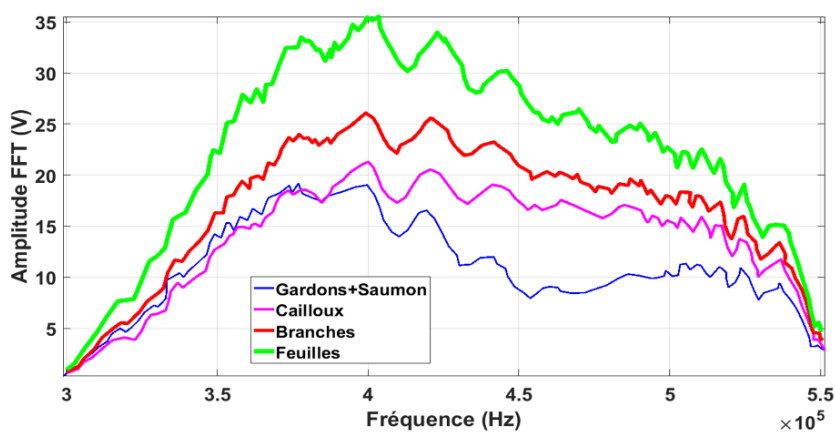

Fig. 5. Spectrum of the acoustic signatures for each target.

Regarding the trout acoustic signatures, statistical analysis of spectra reveals the decrease in energy, which is linked to each fish passage, is consistent over several representative independent measurements. Fig. 6 illustrates the percentile analysis (median - 50\%, maximum - $95 \%$ and minimum - 5 $\%)$. In case of a clear acoustic channel, each spectrum superposes almost perfectly, indicating thus a performant calibration algorithm was applied.

In our experimental setup, the validation of the fish acoustic monitoring measurements has been carried out using an 

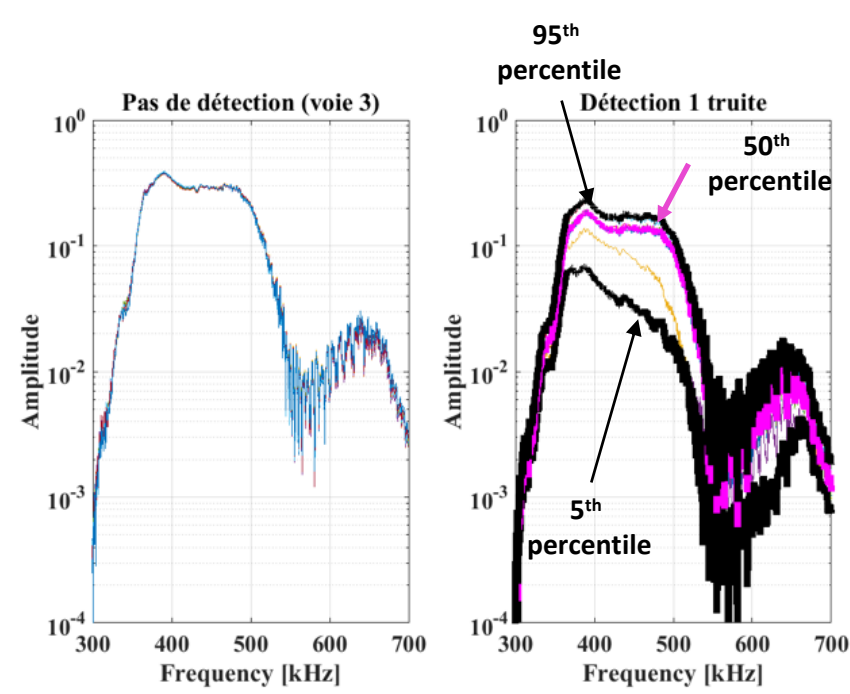

Fig. 6. Statistical analysis of the acoustic signatures (spectrum): (left) for the clear acoustic channel and (right) for the trout target.

underwater video camera which operates independently and continuously throughout the experiment. Fig. 7-(a) shows the expert visual validation procedure: the RMS signal is analysed in conjunction with the recorded video stream.

In order to be able to perform a more detailed analysis of the recorded acoustic signatures, sub-band decomposition has been applied.

The received signal is band pass filtered such as:

- Band 1: [350, 400] kHz,

- Band 2: [400, 450] kHz,

- Band 3: [450, 500] kHz,

- Band 4: [500, 550] kHz,

- Band 5: [550, 600] kHz,

- Band 6: [600, 650] kHz,

- Full bandwidth: $[350,650] \mathrm{kHz}$.

For each band, the RMS value has been computed for each received ultrasound burst. Such RMS curves computed by subbands of $50 \mathrm{kHz}$, in the nominal bandwidth of the system, are illustrated in the Fig. 7-(b).

Several parameters are stored and analysed for recognition purposes (chirp rate and nonlinearity coefficients). The monitoring of the channel $(2 \times 1.5 \times 10 \mathrm{~m})$, with several trouts within, shows a clear pattern of the movement of fish during the 12 hours of monitoring (at night): detections in the first hours of deployment and less activity toward morning because the trouts accommodated to their new environment. These observations are consistent throughout all sub-bands, hence the reliability of the RMS based detection scheme has been demonstrated.

\section{CONCLUSION}

In conclusion, this paper proposed a novel IoT active acoustic system for fish monitoring with direct application in biodiversity preservation near hydropower plants and dams.
The system uses a cost effective single board computer for data acquisition and it is processing acoustic signals at two levels: the first at the board level (embedded), to decide upon transmission of data to a server, and the server level to show the results of detection and the number of fish passages (acoustic signature analysis).

One future direction for improving the detection results is to employ a spatially adaptive clustering [5], [6] or likelihood ratio testing [7] of the acoustic signatures based on the total energy.

We also conclude that this solution is suited to large scale deployment given its relatively low cost and energy effectiveness. This is achieved by taking advantage of the last IoT technological capabilities both in terms of hardware and software.

\section{ACKNOWLEDGMENT}

This work has been developed in the framework of the ACOUEAU project, supported by the European Union Regional Development Fund, the SCANUS project, supported by the SATT LINKSIUM Grenoble Alpes, and the Scientific Equipment 2017 AO project, supported by the LabEx OSUG@2020. The authors would like to thank to Gelu Ionescu, Steeve Zozor, Amaury Nègre and Teodor Petrut, form the GIPSA-lab, and to Géry Hachet and Alexandre Girard, from the EDF R\&D, for their precious support in hardware and software development.

\section{REFERENCES}

[1] European Parlament, "Proposal for a DIRECTIVE OF THE EUROPEAN PARLIAMENT AND OF THE COUNCIL on the promotion of the use of energy from renewable sources (recast)," Tech. Rep. COM/2016/0767 final - 2016/0382 (COD), 2016.

[2] D.A. Demer, L. Berger, M. Bernasconi, E. Bethke, K. Boswell, D. Chu, R. Domokos, A. Dunford, S. Fassler, S. Gauthier, L.T. Hufnagle, J.M. Jech, N. Bouffant, A. Lebourges-Dhaussy, X. Lurton, G.J. Macaulay, Y. Perrot, T. Ryan, S. Parker-Stetter, S. Stienessen, T. Weber, and N. Williamson, "Calibration of acoustic instruments," Tech. Rep. ICES Cooperative Research Report No. 326, 2015.

[3] G. Vasile, G. d'Urso, E. de Oliveira, and E. Lungu, "Transmission waveform analysis for active ultrasound fish monitoring systems," in Proceedings of the MTS/IEEE North American OCEANS conference, Anchorage, Alaska, USA, 2017, pp. 1-4.

[4] G. Vasile, G. d'Urso, E. de Oliveira, and E. Lungu, "Online software nonlinearity correction for wideband active ultrasound monitoring systems," in Proceedings of the MTS/IEEE North American OCEANS conference, Anchorage, Alaska, USA, 2017, pp. 1-4.

[5] G. Vasile, E. Trouvè, M. Ciuc, P. Bolon, and V. Buzuloiu, "Intensitydriven-adaptive-neighborhood technique for POLSAR parameters estimation," in Proceedings of the IEEE Geoscience And Remote Sensing Symposium, Seoul, Korea, 2005, vol. 8, pp. 5509-5512.

[6] G. Vasile, Imagerie Radar à Synthèse d'Ouverture interférométrique et polarimétrique. Application au suivi des glaciers alpins, Ph.D. thesis, Université de Savoie - Annecy, 2007.

[7] N. Besic, G. Vasile, J.P. Dedieu, J. Chanussot, and S. Stankovic, "Stochastic approach in wet snow detection using multitemporal SARdata," IEEE Geoscience and Remote Sensing Letters, vol. 12, no. 2, pp. 244-248, 2015. 


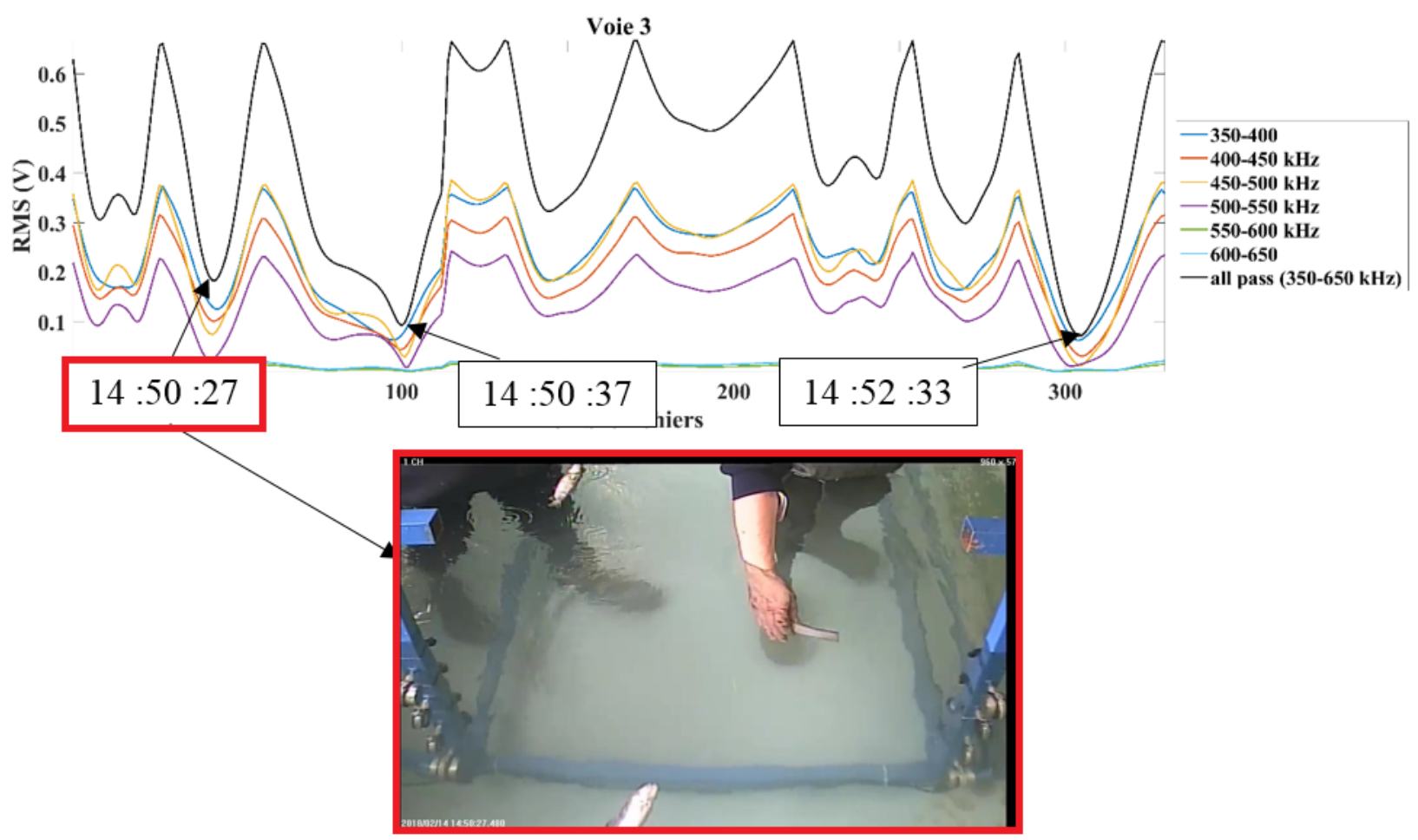

(a)
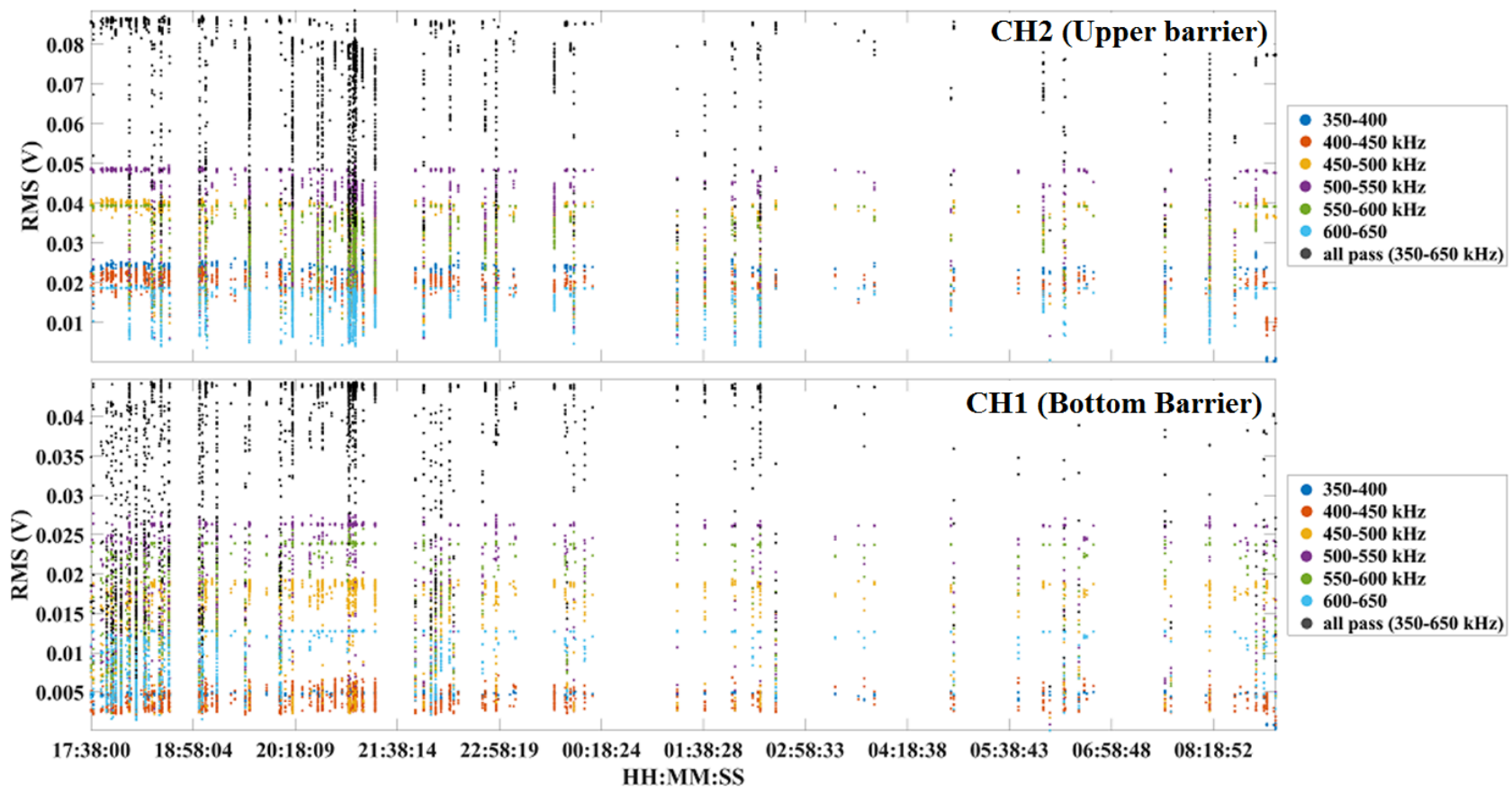

(b)

Fig. 7. RMS curves showing passages of trouts: (a) as validated by the underwater video camera and (b) one night results and the corresponding sub-band decomposition. 